\title{
WISKUNDE IN SUID-AFRIKA*
}

By 'n geleentheid soos hierdie is die versoeking nogal sterk om retrospektief te werk te gaan en 'n poging aan te wend om die verlede soos dit in eie persoon belewe is, die revue te laat passeer. Dit is miskien nie meer as natuurlik nie dat 'n mens dan meer geneig voel om op die afgelegde weg terug te kyk as om jou aan koersaanuysing vir die toekoms te waag. Vir die meeste van $u$, geagte oudstudente, is wat verby is nie van soveel belang as wat die hede aanbied of die toekoms in sy skoot het nie. $M y$ taak nader sy einde, $u$ werk lê hopelik nog vir die grootste gedeelte voor $u$. Wel is dit 'n troosryke gedagte wat $u$ my sal vergun om te koester, dat die band wat daar tussen u en my gelê is, ook in vakkundige opsig nie finaal deurgesny is toe die dae van regstreekse, persoonlike kontak verby was nie. Die onderwyser is nou maar eenmaal so onbeskeie om in die loopbaan en prestasies van sy leerling tot ' $n$ mate 'n verlengstuk van sy eie werk te sien.

Miskien het $\mathrm{u}$ verwag dat ek met $\mathrm{u}$ nie oor Wiskunde nie, maar Wiskunde gaan gesels? Dit sou geen onredelike verwagting gewees het nie waar ons hier as wiskundiges bymekaar is, iets wat uiteraard so selde kon gebeur. Miskien sou ek my wel daaraan gewaag het as ek ietwat eerder van hierdie vererende geleentheid kennis gedra het. Nou is my egter die moontlikheid van 'n groot verleentheid bespaar: die vermetelheid naamlik om aan hierdie gehoor 'n wiskundige voordräg te moet lewer wat vir $\mathrm{u}$ enigsins die moeite werd sou wees om aan te hoor.

Presies twee jaar gelede was dit my groot voorreg om die Internasionale Kongres vir Wiskundiges te Amsterdam by te woon. Sowel wat die plekke van herkoms van die deelnemers as wat die behandelde stof betref, was die byeenkoms inderdaad verteenwoordigend. So groot was die belangstelling en so vol die program dat die vlot verloop van sake alleen deur 'n puik organisasie verseker kon word. Daaraan het dit egter nie geskeel nie en die reëlingskomitee met prof. J. F. Koksma van die V.U. as sekretaris het alle eer vir hulle skitterende werk.

* Rede deur wyle prof. D. J. van Rooy gehou by geleentheid van sy $60 \mathrm{e}$ verjaarsdag, 18 September 1956. 
Ek is nie van plan om oor die kongres en sy werksaamhede uit te wy nie, dit is alles reeds ou nuus. In die verbygaan kan ek egter nie nalaat nie om met waardering daaraan te herinner dat die enigste Afrikaner wat 'n bydrae tot dic program gelewer het, 'n oudstudent van die P.U. vir C.H.O. was, nl. mnr. (nou dr.) D. J. Stoker, wat 'n kort voordrag oor 'n statistiese onderwerp ten beste gegee het. Ek noem die kongres hoofsaaklik omdat dit ' $n$ mens ' $n$ totaal-indruk gegee het van die verbasende bedrywigheid op die wiskundige front. Opvallend was ook die groot aantal jongeres wat met onderskeiding voor die uitgelese gehoor kon optree. Wat die stof betref, het die suiwere Wiskunde natuurlik in al sy vertakkinge aandag geniet, maar ook die Toegepaste Wiskunde was goed verteenwoordig, o.a. die Statistiek en Waarskynlikheidsrekening. Trouens, my indruk was dat daar so effe 'n swaartepuntsverskuiwing van die uiters abstrakte na die meer konkrete te bespeur was. Die grondslae en wysbegeerte van die Wiskunde het minder aandag geniet; miskien is die matematici vereers uitgepraat oor hierdie belangrike aangeleentheid of het hulle ooreengekom om daaromtrent te verskil. Vir my was dit altans ' $n$ teken des tyds dat my hooggeagte leermeester, prof. dr. L. E. J. Brouwer, erkende outoriteit op genoemde gebied, die kongres nie bygewoon het nie. Wanneer mens 'n gebou oprig, kan jy egter nic vir onbepaalde tyd by die fondamente vertoef nie, daar moet verder gebou en eventueel moet die gebou tog ook in gebruik geneem word. Waarskynlik is dit die houding van die huidige geslag: laat wie wil maar aanhou kibbel oor die deugsaamheid, al dan nie, van die grondslae, ons bou voort.

'n Laaste verwysing na die kongres. Ek kon heelwat van die verrigtinge van die afdeling bywoon waar o.a. gehandel is oor die Didaktiek en Metodiek van die Wiskunde. Uitgesoekte sprekers uit verskillende lande het die vraagstuk van die vorming van die jeugdige wiskundige uit sowel teoretiese as praktiese standpunt behandel. Teoreties, deeglik, swaar op die hand, die Duitser; prakties, pragmaties, aanskoulik, die Amerikaner. Tussen die twee uiterstes: Nederlander, Deen, Brit en Fransman. Ook in die besprekinge is standpunte gestel, aangeval en verdedig. Oor een aspek was almal dit eens: die opleiding van die M.S.-onderwyser is die werk van die universiteit, maar dan met die uitdruklike voorwaarde dat aan die eise van 'n gesonde en vooruitstrewende Didaktiek en Metodiek 
ernstige aandag geskenk sal word. Dat die onderwyser goeie vakman moet wees, word as vanselfsprekend aanvaar. Of so 'n opleiding in die praktyk spoedig verwesenlik gaan word, is 'n ander kwessie. Ek herinner my dat dit reeds in 1935 in Nederland as 'n dringende behoefte aangevoel is, en in 1954 het die behoefte nog ewe dringend voortbestaan.

Hiermee het ons op ' $n$ gerieflike punt beland om by die toestande in ons eie land aan te skakel. Eerstens die Middel. bare Skool. In die kort bespreking wat ek aan die onderwys van die Wiskunde aan die M.S. wil wy, sal 'n beroep op eie ervaring as M.S.-onderwyser heel aan die begin van my loopbaan nie veel indruk maak nie. Tog meen ek met reg te kan beweer dat die onderwyser in die afgelope 40 jaar nie veel vooruitgegaan het nie, in sekere opsigte stil bly staan of agteruit beweeg het. Moet dit asseblief nie opvat as die beskouing van 'n professor wat uit sy akademiese stoel en stand. punt geneig is om alle pre-universitêre vakonderwys ligtelik te veroordeel nie. Ek het my jarelank beywer om met die middelbare onderuys en die onderwysers in noue voeling te bly; ek het artikels in onderwysblaaie geskrywe, aan hulle resensies besorg, op kongresse opgetree. Helaas, sonder sigbare resultaat, wat seker in die eerste plek aan my tekortkominge te wyte is, maar darem ... Die professor word so maklik daarvan verdink dat hy uitsluitend die behoeftes van die aankomende student in die oog het en nie rekening hou met die oorgrote meerderheid wat nooit die Universiteit gaan binnetree nie. Laat ons erken dat so 'n vermoede nie altyd sonder enige grond is nie. Aan die ander kant moet die skool met die feit rekening hou dat die universiteit op geen ander manier as via die M.S. sy studente kan bekom nie en dat hy van hulle binne die kort bestek van 3 jaar redelike wiskundiges moet maak.

Is die universiteit onredelik in sy eise? Die Matrikulasieraad is op die oomblik besig om 'n hersiene Wiskunde-leerplan op te stel. Dit is 'n poging om 'n gemeenskaplike leerplan te besorg. Word dit nie as sodanig deur die provinsiale departemente aanvaar nie - en dit sal hoogswaarskynlik die geval wees - is die gedagte tog dat dit as model-leerplan gehand. haaf sal word en die minimum vereistes vir toelating tot die universiteit, in elk geval tot sekere fakulteite, behoort te verteenwoordig. Die meeste van $\mathrm{u}$ het vermoedelik reeds die konsepleerplan ter insae gehad, daarom hoef ek dit nie in 
besonderhede te bespreek nie. U sal my seker toestem dat dit nie die onmoontlike beoog nie. Waar sekere dinge bygevoeg is, word andere weggelaat. As die onderwyserskorps maar die gees van die voorstelle wil verstaan en aanvaar, kan ons baie gou tot 'n ooreenkoms geraak. Op een of ander manier sal gedifferensieer moet word tussen die leerling wat hoogstens 'n Skooleindsertifikaat se kennis van Wiskunde wil verwerf en die leerling vir wie die vak 'n voorvereiste vir verdere studie gaan wees. Sonder oordrywing meen ek te mag beweer dat die wiskundigbegaafde leerling hom gedurende die laaste helfte van sy Matrikulasiejaar deerlik verveel en gevaar loop om al sy belangstelling in en smaak vir die vak te verloor. Aan die ander kant het ons die eerstejaar-student wat met ' $n$ A-syfer hom vol vertroue op 'n wiskundige loopbaan kom toelê, en dan moet uitvind dat hy gememoriseerde kennis vir aanleg aangesien het.

Waar lê die fout? Ongetwyfeld is die vereistes vir die Skooleindeksamen verslap. Die kandidate kom voor 'n eksterne eindeksamen te staan en 'n stereotipe voorbereiding vir 'n stereotipe eksamenvraestel lewer die grootste diwidend. Bewaar die eksaminator of moderator wat met sy vrae 'n jota of titel van die tradisionele styl of inhoud afwyk! Selfs die eksamenterminologie is geyk. Dit is waarskynlik een van die redes waarom geen ryker versameling van Anglisismes aangetref kan word as in die Afrikaanse handleidings en eksamenstelle vir die M.S.-Wiskunde nie. Voorbeelde sal ek u bespaar, die saak sal hopelik eersdaags in 'n tydskrifartikel behandel word. Te veel mag ons die vakonderwyser van die M.S. nie blameer nie. Feit bly egter dat 'n ongesonde konservatisme hom aan bande lê. Het hy al een enkele blyk van 'n eie visie op die Wiskunde-onderwys gegee? Laat ek my bepaal by die Afrikaanssprekendes. Heelwat leerboeke het al verskyn, waaronder ' $n$ aantal vertaaldes. Laasgenoemdes wend ' $n$ poging aan om werke wat met ' $n$ meerdere of mindere mate van sukses in hulle Engelse gedaante jarelange diens bewys het, nou in Afrikaans te verewig. Ons ou vriend "Hall” is ,a case in point". As ons middelbare skole nog nie kans sien om die leiband te los nie, waarom nie ook van Nederlandse en Duitse leerboeke kennis neem nie? Selfs in Engeland begin die mense daarvan blyk te gee dat Perry en Nunn nie tevergeefs gelewe en geleer het nie. Ek vrees dat te min van ons kollegas in die M.S. deeglik kennis neem van wat in die ou kultuurlande 
en in Amerika op die gebied van hulle vak aangaan. 'n Opname van die vaktydskrifte wat deur hulle ingesien word, sou waarskynlik tot nadenke stem. Om nie eens te wys op die algehele gebrek aan enigiets van dié aard wat in Afrikaans (of in Engels) in Suid-Afrika verskyn nie !

U sal my die ietwat gerekte uitweiding oor die toestande in die voorportaal van die universiteit nie kwalik neem nie. In 'n afloswedren moet elke lid van die span geduldig op sy pos staan en wag en kan hy nie die aankomende lid tegemoet hardloop om die pand eerder oor te neem nie. En die eindresultaat hang van elke lid van die span af al is dit die laaste man wat die lint moet breek. Hiermee beland ons dan ten laaste op eie terrein.

Die taak van die universiteitsdosent is tweëerlei, nl.: 1. die opleiding van sy studente en 2 . navorsing.

\section{Opleiding.}

(a) Die dosent: Wyle prof. A. E. du Toit het meermale beweer dat die bekwaamheid van die dosent nie beoordeel moet word volgens die aantal studente wat onder sy leiding in die eksamen slaag nie, maar aan die aantal druipelinge. As hy homself volgens hierdie maatstaf gemeet het, het hy alle rede gehad om hoog in eie estimasie te staan. Dit was "to do or to die" by hom. Arme eerstejaarstudent wat met "A.E." te doen gekry het! Ek ag my gelukkig dat ek ná die M.S. in die hande van prof. J. H. Woolston (G.U.K.) beland het. Hy was 'n onderwyser soos ek weinig teëgekom het. In sy hande het die Wiskunde getintel en gefonkel. Die weinige wat ek later as vakonderwyser kon presteer, het ek grotendeels aan sy inspirerende voorbeeld te danke gehad. Nogtans sal ek nooit vergeet hoeveel ek aan prof. A. E. du Toit verskuldig is nie. Soos weinige kon hy daarin slaag om sy student voor die onverbiddellike eise van sy volk te stel. Sy houding was 'n gedurige uitdaging en prikkel. Wou of kon jy daarop nie ingaan nie, dan liewer dadelik die stryd gewonne gee. Buk jy om die handskoen op te tel, verwag dan geen genade nie. Jy moet Wiskunde, lees, in alle moontlike vertakkinge en in alle moontlike of onmoontlike tale. Persoonlik moes ek ' $n$ leeskennis van Duits en Frans opdoen om my genadelose leermeester enigsins te bevredig. Vir my het hy egter die poort tot die hoër Wiskunde ontsluit. 
(b) Die student: A. E. du Toit, die professor, en Woolston, die onderwyser. Ons is geroepe om iets van beide te wees. Seker is dit nodig om so spoedig moontlik die koring van die kaf te skei, by ons miskien meer as in enige ander vak. Moes die leerling op die M.S. noodgedwonge Wiskunde enduit neem, nou staan vir hom ander rigtinge oop en kan hy 'n wye draai om die Wiskunde en die wiskundiges loop. Waag hy hom egter binne ons kollegesale, dan kan ons met reg verwag dat hy die nodige aanleg besit en die nodige toeleg gaan toon. Anders is dit slegs in sy voordeel om hom baie gou te ontnugter. Aan die ander kant is menige veelbelowende jong student deur die onsimpatieke optrede van die dosent afgeskrik alvorens hy in die nuwe omstandighede goed koers kon vat. Dit neem tyd en geduld om hom van die lepelvoeding te speen en hom tot die besef te bring dat Wiskunde nie soveel ' $n$ leervak as ' $n$ doenvak is nie. Wat die aanbieding en behandeling van die stof betref, meen ek dat die Wiskunde-dosent in die reël die nodige aandag aan metode skenk en steeds gewillig is om sy studente by te staan. Hieraan doen hy soms meer as wat redelikerwys van hom verwag kan word, en ek vrees dat ons geneig is om te veel skoolmeester te speel. Hoe eerder die student besef dat die onus op hom rus, hoe beter. Die tempo neem steeds toe, die dosent word al meer die wegwyser, nie die voor- of saamloper nie. Hy (die dosent) moet tog seker die tyd en geleentheid gegun word om nuwe weë in die woud van die wetenskap te baan, hy kan nie altyd op reeds ontgonne terrein vertoef nie.

(c) Leerstof: In die Nederlandse universiteite gaan elke dosent in die Wiskunde min of meer sy eie gang in die spesiale onderdeel of onderdele van die vak wat aan hom toegewys is of meer bepaald sy aandag geniet. Dit mag wees dat hy oor 'n onafgebroke tydperk van twee of drie jaar daarin kollege gee en daarby 'n progressiewe gang volg. Die inkomende student moet maar inval as hy kans sien, of ander kolleges bywoon tot tyd en wyl hierdie dosent sy draai gemaak het en weer voor begin. Vir die dosent het dit die groot voordeel dat hy (i) minder kolleges gee, (ii) hom intensief aan 'n bepaalde deel van die Wiskunde kan wy en (iii) aan publikasies ook aandag kan skenk. Vir die student wat "by" is, het dit die voordeel dat hy (i) aan die voete van iemand sit wat op daardie bepaalde gebied volkome tuis is, en (ii) die 
Wiskunde as 't ware ,in die maak" kan sien. Hy kry dus die gevoel dat hy besig is om saam te bou en hom selfstandig. krities teenoor eie werk en die werk van ander te staan. Hier maak dit nie veel saak watter stof in 'n gegewe semester behandel word nie, want die verskeidenheid wat oor 'n twee, drie jaar aangebied word, is gewoonlik so groot dat die student geen moeite ondervind om, onderworpe aan sekere algemene bepalings, volgens eie smaak en keuse vir homself 'n leergang uit te werk nie. As daarby in aanmerking geneem word dat die eksamendatum in hoofsaak deur die kandidaat self bepaal word, moet ons erken dat die stelsel groot voordele bevat. Sal ons dit egter net so wil of kon oorneem? Eerstens is ons stelsel heeltemal op Engelse lees geskoei en sou dit 'n ware omwenteling kos om daarvan los te kom. Tweedens bevat ons huidige stelsel onteenseglik sekere goeie eienskappe wat by die Kontinentale ontbreek, veral vir die betreklik onrype student met wie ons te doen kry. Ons sal nog ' $n$ eie stelsel moet ontwikkel, dit is een van die take wat die jonger geslag sal moet onderneem. Vir die huidige sit ons nog vas in die tradisionele gang van ' $n$ vaste leerplan vir elke studiejaar, afgesluit deur 'n eksamen aan die einde van die jaar. In die eerste jaar moet ons darem, al is dit met die punte van ons vingers, die hand van die M.S. kan aanraak. Die werk van elke volgende jaar is grotendeels ' $n$ voortsetting van die vorige jaar se program. So word vir die B.Sc. graad met Wiskunde as hoofvak, drie jaar bestee aan elk van Algebra, Analitiese Meetkunde en Infinitesimaalrekening; een jaar aan Trigonometrie en Goniometrie terwyl die Sintetiese Meetkunde, sowel twee- as driedimensionaal, feitlik heeltemal uit die leerplan verdwyn het. So tripliseer ons die lesings in elke onderdeel van die vak. Hoofskotel is beslis die Analise, waarskynlik vir 'n groot deel te danke (of te wyte) aan die al of nie uitgesproke behoeftes van die toegepaste gebiede (Meganika, Fisika, Statistiek ens.), wat blykbaar nooit genoeg hulpmiddels aan die Analise kan ontleen nie. Die wiskundige sy gewaarsku: al is dit 'n strelende gedagte dat ons kollegas van die aangrensende gebiede voetstoots die eminensie van sy vak moet erken, selfs sover gaan dat hulle graag van hulle „matematiese" natuurwetenskappe aanhaal; en al erken die matematikus op sy beurt geredelik dat hy baie van sy inspirasie uit hulle ondersoekinge put; kan die wiskundige die inhoud en behandeling van sy leerplan nie deur daardie mense en 
hulle belange laat voorskryf nie. Met behoorlike inagneming van sy buurvakke moet die Wiskunde nogtans outonoom wees op eie gebied. Vandaar dat dit te betreur sou wees as sulke belangrike vertakkinge soos die suiwere Ruimteleer, die Grondslae-studie en selfs die behoorlike logiese fundering van elke deel van die vak aan die eise van toepassing op natuurwetenskaplike of tegniese gebied opgeoffer sou word. Aan die P.U. vir C.H.O. wil ons graag die nouste kontak en onderlinge oorleg met mekaar handhaaf - dit word trouens gesimboliseer deur die broederlike samewoning van Fisika, Wiskunde, Toegepaste Wiskunde en Statistiek in een gebou, met Chemie as naaste buurman - maar ons besef terdeë dat ons alleen dan die beste diens aan mekaar kan lewer as elk sy eie potensialiteite so goed en sover moontlik ontwikkel.

En nou wat betref die Onderwysersopleiding. Vir my was dit altyd opvallend hoeveel belang die meeste Wiskundedosente in hierdie saak stel. Selfs prof. A.E. het die U.O.D.werk besonder ernstig opgeneem. Van die Metodiek, Dedaktiek en die Geskiedenis van die Wiskunde moes 'n deeglike studie gemaak word en aan die Grondslae is besondere aandag gewy. So was dit altans in die ou dae van die Universiteit van SuidAfrika en so is dit, na ek meen, aan die meeste Suid-Afrikaanse Universiteite nog die geval. Gewoonlik moet die dosent kla dat die U.O.D.-leergang te min tyd vir 'n behoorlike behandeling van die wiskundige program toelaat. Die U.O.D.-jaar leen hom anders so pragtig daarvoor dat die student sy vak 'n bietjie wysgerig kan betrag. Sy voorgraadse jare moes hy noodwendig aan die tegniek van die vak bestee, nou kan hy enigsins ' $n$ oorsig kry, en daarmee 'n wyer blik op die struktuur van die Wiskunde nie alleen nie, maar ook op sy samehang met grensgebiede en die wetenskap as geheel. Vir die eerste keer kom hy dan pertinent voor die vraag van 'n prinsipiële standpunt te staan en leer hy insien dat lewens- en wêreldbeskouing oral, dus ook in die wiskundige wetenskappe, 'n rol speel. Terloops kan in hierdie verband melding gemaak word van die onlangs ingevoerde kursus in Beginsel- en Metodeleer wat ook vir die toekomstige onderwyser van groot betekenis kan wees. „Wie slegs Wiskunde ken, ken selfs Wiskunde nie", is een van my geliefkoosde lyfspreuke. Op besonderhede insake leerplanne en leerstof gaan ek nie in nie, liewer bepaal ek u aandag vir 'n oomblik by die leerboek: 
(d) Die leerboek: Die Afrikaanssprekende eerstejaarstudent kan op die M.S. van Afrikaanse handleidings gebruik maak. Dit was beslis in sy voordeel al bestaan daar rede vir 'n minder gunstige beoordeling van sommige van die leerboeke. Oor die hoër Wiskunde het daar, sover ek weet, tot op datum slegs een Afrikaanse handleiding die lig gesien, tien jaar gelede. Die student word gevolglik genoodsaak om Engelse boeke te gebruik. (Nederlandse en Duitse is bo sy vuurmaakplek). Nou is dit waar dat 'n student so spoedig moontlik die biblioteek moet leer gebruik en hom daarby nie tot sy moedertaal moet beperk nie. Eers moet hy egter sy handleiding kan hanteer en hier moet bykomstige moeilikhede soos vreemde voertaal soveel moontlik wyk. Buitendien is dit vir ons van die Afrikaanse Universiteite 'n kultuurtaak en -plig om leerboeke in ons eie taal te verskaf. Dit gaan tog immers ook nie net om die taal nie, maar verwag kan word dat ons so langsamerhand die vakliteratuur met handleidings moet verryk wat opgestel is volgens ' $n$ eie styl en siening. Waarlik as ek aan ons onbegryplike traagheid in hierdie opsig dink, voel ek geneig om alles terug te trek wat ek oor die Afrikaanse handleidings van die M.S. gesê het. Daar is tog al iets gedoen, wat doen óns? Een vraag moet my van die hart: As Afrikaanse Universiteit A sover kom om 'n verdienstelike handleiding te produseer, (en dit vereis moed en geloof sowel by skrywer as by uitgewer), sal Afrikaanse Universiteit B daarvan gebruik maak of die hele onderneming eenvoudig negeer?

\section{Navorsing:}

My onderwerp lui: „Wiskunde in Suid-Afrika” en nie: „Suid-Afrikaanse Wiskunde" nie. Kort voor die jongste Wêreldoorlog het daar in Duitsland 'n tydskrif verskyn getitel „Deutsche Mathematik”. Die strewe was o.a. om selfs in die Wiskunde volgens Nasionaal-sosialistiese patroon eie goed van vreemde goed te onderskei. Afgesien van ideologiese oordrywing kon die Duitser tog met 'n groot mate van reg van so iets soos 'n Duitse Wiskunde gewag maak. Wat het die Wiskunde nie aan Duitse matematici te danke nie? Van die allergrootstes word in hulle geledere aangetref. En onteenseglik bestaan daar so iets soos 'n Duitse styl in die Wiskunde. Dink aan die werk van Gauss, van Riemann, aan Hilbert se groot invloed op die gebied van die Wysbegeerte van die Wiskunde; aan die wiskundig-pedagogiese werk van Klein, Lietzmann e.a. Die 
mens het 'n eie stempel op hulle werk afgedruk. So iets tref ons ook by die Franse en ander volke aan. Hoe internasionaal die Wiskunde ook mag wees, dit dra gewoonlik 'n geboortemerk.

Bestaan daar reeds so iets soos 'n Suid-Afrikaanse Wiskunde? Wel kan ons ons verheug in die bestaan van SuidAfrikaanse, ja selfs Afrikaanse, wiskundiges; hierdie byeenkoms getuig daarvan. Maar 'n Suid-Afrikaanse Wiskunde? Miskien moet ons dit liewer 'n ope vraag laat. Nie dat daar nie al verdienstelike oorspronklike werk deur Suid-Afrikaanse matematici gelewer is nie. Maar hulle gaan oorsee om dit te doen, bv. by wyse van proefskrif. Waar die aanleg en die drang vir verdere produktiwiteit bestaan, vind ons dat so 'n begaafde Suid-Afrikaner sy vaderland vir goed verlaat en sy talente elders beskikbaar stel. 'n Enkele publikasie van die hand van iemand in S.A. verskyn nou en dan in 'n buitelandse tydskrif. Tot 'n eie vakblad in S.A. of selfs 'n Matematiese Vereniging kon ons nog nie geraak nie. Ek glo nie dat iemand daarvoor te blameer is nie, die tyd is waarskynlik nog nie ryp daarvoor nie. Daarmee ontbreek egter nog 'n baie belangrike prikkel tot getroue, ingespanne navorsing op wiskundige gebied in ons land. Verder het ons stelsel die groot nadeel dat die dosent soveel tyd aan lesings en nasienwerk moet gee dat hy moeilik aan sistematiese navorsing kan kom. Waar die toestand in hierdie opsig geleidelik verbeter, sal personeellede seker in die toekoms meer selfstandige werk kan lewer, ook hulle nagraadse studente daartoe aanmoedig en hulle die nodige leiding gee. Dit is seker vandag nog slegs by uitsondering dat die doktorsgraad in die Wiskunde in S.A. behaal word. Gewoonlik gaan die student ná behalings van die Magistersgraad vir verdere studie oorsee. Persoonlik het ek dit nog altyd baie sterk aangemoedig. Om vir die Magisterseksamen ' $n$ verhandeling van enige betekenis te verwag, is m.i. 'n verspilling van tyd en energie. Na my mening het die kandidaat dan nog al sy tyd nodig om 'n afgeronde kennis van 'n wye gebied en 'n meer gespesialiseerde kennis in ' $n$ bepaalde rigting te bekom. Dan eers sou hy hom in alle erns op eie ondersoek kon toelê.

Die tyd moet kom en het miskien reeds aangebreek dat elke Wiskunde-dosent 'n bepaalde rigting in sy vak moet inslaan en dit sy lewenstaak maak. Vroeër was ons min in aantal en moes ons ons noodwendig daarop toelê om 'n bietjie 
van alles te weet liewer as alles van ' $\mathrm{n}$ bietjie, om sodoende nie elke gevorderde student in dieselfde rigting te forseer nie maar elk die kans te gee om 'n eie keuse te kon doen. Hoe onbevredigend dit baie maal vir 'n mens self was, daarmee was dan tog die grondslag vir 'n groter verskeidenheid in die toekoms gelê.

So 'n O.K.-bestuurder van wiskundige uare was ek. Nooit het ek dit gewaag om onbekendheid met 'n studierigting te bely waarin ' $n$ student blyke van belangstelling en aanleg getoon het nie - ek het maar net geprobeer om een of twee lesings voor hom te bly. Dat my studente steeds gemaak het asof hulle dit nie agtergekom het nie, is vir my 'n rede tot dankbaarheid. Dat hulle, nadat hulle van my attensies ontslae was, hul eie koers verder kon vind, was 'n vervulling van my innige begeerte. Laat my toe om teenoor $u$, geagte oudstudente, met ' $n$ bekentenis voor die dag te kom. My regte plek was nooit aan 'n universiteit nie, ek moes aan 'n M.S. gebly het en dit was ook my begeerte. Ek is egter daar weg. geroep en ek het die roepstem opgevolg. Daarin wil ek die leiding van God sien. Dit was - en is nog steeds - my voorreg om in die ry van my studente telkens weer besonder goeie talent te ontdek. Daarom kon P.U. deur die jare eerder meer as minder gevorderde studente lewer as wat volgens sy getalle verwag sou word. Hulle staan dan ook hulle plekke met eer en onderskeiding vol. In soverre ek daarin vrug op my arbeid mag sien, dank ek God dat Hy dit in sy genade so beskik het. Ain Hom die eer. 